2. Аргучинцев А. В. Оптимальное управление: нелокальные условия, вычислительные методы и вариационный принцип максимума / А. В. Аргучинцев, В. А. Дыхта, В. А. Срочко // Известия высших учебных заведений. Математика. - 2009. - № 1. - С. 3-43.

3. Габасов Р. Принцип максимума в теории оптимального управления / Р. Габасов, Ф. М. Кириллова. — М. :Либроком, 2011. - 272 с.

4. Кларк Ф. Оптимизация и негладкий анализ / Ф. Кларк. - М. : Наука, 1988. - 280 с.

5. Кротов В. Ф. Методы и задачи оптимального управления / В. Ф. Кротов, В. И. Гурман. - М. : Наука, 1973. - 446 с.

6. Математическая теория оптимальных процессов / Л. С. Понтрягин, В. Г. Болтянский, Р. В. Гамкрелидзе, Е. Ф. Мищенко. - М. : Физматлит, 1961. - 388 с.

7. Никольский M. C. О достаточности принципа максимума Понтрягина в некоторых оптимизационных задачах / М. С. Никольский // Вестник Московского университета. Сер. 15, Вычислительная математика и кибернетика. - 2005. - № 1. - С. 35-43.

8. Срочко В. А. Достаточные условия оптимальности в задачах управления на основе формул приращения функционалов / В. А. Срочко, В. Г. Антоник, Е. В. Аксенюшкина // Известия Иркутского государственного университета. Сер. Математика. — 2014. — Т. 8. - С. 125-140.

9. Срочко В. А. Достаточные условия оптимальности экстремальных управлений на основе формул приращения функционала / В. А. Срочко, В. Г. Антоник // Известия высших учебных заведений. Математика. - 2014. - № 8. - С. 96-102.

10. Срочко В. А. Итерационные методы решения задач оптимального управления / В. А. Срочко. - М. :Физматлит, 2000. - 160 с.

\title{
Апекова А.O. \\ Оценка вероятности банкротства по методикам адаптированным к российской экономике
}

Кузбасский государственный технический университет имени Т. Ф. Горбачева

(Россия, Кемерово)

doi:10.18411/spc-8-12-2017-03

idsp: 000001:spc-8-12-2017-03

Банкротство (несостоятельность) - признанная арбитражным судом или объявленная должником неспособность должника в полном объеме удовлетворить требования кредиторов по денежным обязательствам и (или) исполнить обязанность по уплате обязательных платежей [1].

Целью анализа вероятности банкротства является оперативное выявление близости к несостоятельности и применение необходимых мер в избежание данного состояния. Каждая из методик имеет право на существование, хоть и основываются на различных факторах. Для оценки вероятности банкротства АО «XXX» целесообразно рассмотреть следующие модели:

- методика Министерства финансов;

- четырехфакторная иркутская модель Беликова-Давыдовой;

- модель О.П. Зайцевой;

- модель Г.В. Савицкой.

Официальные методики созданы на основе отечественных нормативнозаконодательных документов, при помощи методического положения по оценке финансового состояния предприятий и установлению неудовлетворительной структуры баланса (№31 от 12 августа 1994 года) можно оценить вероятность банкротства, применяя систему из трех показателей:

1. Коэффициент текущей ликвидности (L тек. ликв.):

$\mathrm{L}$ тек. лик. $=\frac{\mathrm{A} 1+\mathrm{A} 2+\mathrm{A} 3}{\Pi 1+\Pi 2}$

$\mathrm{L}$ тек. лик. $2015=\frac{23714924}{7709013+20563414}=0,84$.

$\mathrm{L}$ тек. лик. $2016=\frac{26669857}{7884006+9337768}=1,55$.

2. Коэффициент обеспеченности собственными средствами (L об. соб. cp):

$\mathrm{L}$ об. соб. $\mathrm{cp.}=\frac{\Pi 4-\mathrm{A} 4}{\mathrm{~A} 1+\mathrm{A} 2+\mathrm{A} 3}$ 
L об. соб. ср. $2015=\frac{33364538-64558731}{23714924}=-1,32$.

L об. соб. ср. $2016=\frac{36054103-69793699}{26669857}=-1,27$.

3. Коэффициент восстановления платежеспособности (L вос.):

$\mathrm{L}$ вос. $=\frac{L \text { тек.лик. }+\frac{6}{t} * \Delta L \text { тек.лик. }}{2}$

$\mathrm{L}$ вос. $=\frac{1,55+0,5 *(1,55-0,84)}{2}=0,96$.

Для наглядности рассчитанные показатели представлены в таблице 1.

Таблиияа 1

Анализ коэффициентов, используемых при оченке неудовлетворительности структуры баланса по методике Министерства финансов, на примере $A O$ «XXX» за $2015-2016$ г2.

\begin{tabular}{|c|c|c|c|}
\hline Показатели & Нормативное & \multicolumn{2}{|c|}{ Уровень показателя } \\
\cline { 3 - 4 } & значение & 2015 год & 2016 год \\
\hline Коэффициент текущей ликвидности & от 2,0 до 3,0 & 0,84 & 1,55 \\
\hline Коэффициент обеспеченности собственными \\
средствами
\end{tabular}

За 2015 и 2016 годы уровень коэффициента текущей ликвидности не достигает нормативного значения. При этом некоторые авторы определяют нормативное значение коэффициента текущей ликвидности от 1,5 до 2,0, а в 2016 году данный коэффициент имеет значение 1,55 . Это означает, что анализируемое предприятие имеет достаточное количество оборотных активов для покрытия краткосрочных обязательств.

Уровень коэффициентов обеспеченности собственными средствами организации $\mathrm{AO}$ «XXX» в 2015-2016 гг. свидетельствует о том, что предприятие на данный период времени не имеет собственных оборотных средств, необходимых для его финансовой устойчивости.

Таким образом, прослеживается положительная динамика данных показателей, но, ни один из коэффициентов не соответствует нормативным значениям, поэтому является целесообразным расчет коэффициента восстановления платежеспособности $\mathrm{AO} \ll \mathrm{XXX».}$

Коэффициент восстановления платежеспособности рассчитывается на период равный 6 месяцам, это означает, что если коэффициент восстановления платежеспособности больше или равен единице, то у организации есть реальная возможность восстановить платежеспособность за полгода.

При оценке финансового состояния предприятия и вероятности его банкротства по методике Министерства финансов на примере $\mathrm{AO}$ «XXX» было выявлено, что у компании нестабильное финансовое состояние и возможность восстановления платежеспособности и его рентабельности в настоящий момент отсутствует. Таким образом, АО «XXX» не сможет восстановить свою платежеспособность в ближайшие шесть месяцев.

При этом в АО «ХХХ॥ следует провести оценку системы внутреннего контроля и разработать мероприятия по повышению эффективности ее функционирования. Это обусловлено тем, что «система внутреннего контроля организуется в целях обеспечения финансовой устойчивости предприятия, достижения оптимального баланса между ростом его стоимости, прибыльностью и рисками, а также для обеспечения сохранности активов, выявления, исправления и предотвращения нарушений, своевременной подготовки достоверной бухгалтерской (финансовой) отчетности и, тем самым, повышения инвестиционной привлекательности [2]» и снижения вероятности банкротства. 
Четырехфакторная модель Беликова-Давыдовой (Иркутская государственная экономическая академия, 1998 год) - одна из первых отечественных моделей прогнозирования банкротства предприятия, предложенная Александром Юрьевичем Беликовым в своей диссертации в 1998 году, при тщательном руководстве его научного руководителя

Г.В. Давыдовой. Регрессионная формула модели выглядит следующим образом:

$$
\begin{aligned}
& \mathrm{Z}=8,38 * \mathrm{~K}_{1}+1 * \mathrm{~K}_{2}+0,054 * \mathrm{~K}_{3}+0,63 * \mathrm{~K}_{4} \\
& \text { Формулы расчета коэффициентов: } \\
& \mathrm{K}_{1}=\frac{\text { Оборотныйкапитал }}{\text { Активы }} \\
& \mathrm{K}_{2}=\frac{\text { Чистая прибыль }}{\text { Собсвенньйкапитал }} \\
& \mathrm{K}_{3}=\frac{\text { Вьручка }}{\text { Aктивы }} \\
& \mathrm{K}_{4}=\frac{\text { Чистая прибыль }}{\text { Себестоимость }}
\end{aligned}
$$

Для АО «ХXX» формула расчета данной модели в 2016 году имеет следующий вид:

$\mathrm{Z}=8,38 * 0,1+1 * 0,08+0,054 * 0,72+0,63 * 0,06=0,995$.

Оценка предприятия по модели прогнозирования банкротства ИГЭА:

Если $Z<0$, риск банкротства максимальный (90-100\%).

Если $0<Z<0,18$, риск банкротства высокий (60-80\%).

Если $0,18<Z<0,32$, риск банкротства средний (35-50\%).

Если $0,32<Z<0,42$, риск банкротства низкий (15-20\%).

Если $Z>0,42$, риск банкротства минимальный (до 10\%).

Таким образом, по методике оценки вероятности банкротства БеликоваДавыдовой организация АО «ХХX» имеет минимальный риск банкротства (до 10\%).

Следующая модель прогнозирования вероятности банкротства была предложена профессором Ольгой Петровной Зайцевой в 1998 году в Сибирском университете потребительской коммерции. Регрессионная формула расчета данной модели выглядит таким образом:

$\mathrm{K}_{\text {факт }}=0,25 * \mathrm{~K}_{1}+0,1 * \mathrm{~K}_{2}+0,2 * \mathrm{~K}_{3}+0,25 * \mathrm{~K}_{4}+0,1 * \mathrm{~K}_{5}+0,1 * \mathrm{~K}_{6}$

Расчет коэффициентов, используемых в регрессионной формуле:

$\mathrm{K}_{1}=\frac{\text { Приыбль (убыток)до налогообложсения }}{\text { Собственный капитал }}$

$\mathrm{K}_{2}=\frac{\text { Кредиторскаязадолженность }}{\text { Дебиторская задолженность }}$

$\mathrm{K}_{3}=\frac{\text { Краткосроныеобязательства }}{\text { Наиболееликвиднье активы }}$

$\mathrm{K}_{4}=\frac{\text { Прибыль до налогообложения }}{\text { Выручка }}$

$\mathrm{K}_{5}=\frac{\text { Заемный капитал }}{\text { Собственный капитал }}$

$\mathrm{K}_{6}=\frac{\text { Активы }}{\text { Выручка }}$

Регрессионная формула для данной модели на примере $\mathrm{AO}$ «XXX» в 2016 году выглядит следующим образом: $1,39=1,43$.

$\mathrm{K}_{\text {факт }}=0,25 * 0,1+0,1 * 0,47+0,2 * 5,17+0,25 * 0,05+0,1 * 1,68+\quad+0,1 *$

Для определения вероятности банкротства предприятия необходимо произвести сравнение фактического значения интегрального показателя с нормативным значением. Нормативное значение рассчитывается по следующей формуле:

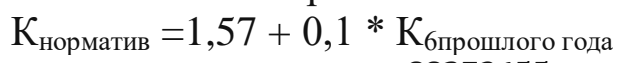

$K_{\text {норматив }}=1,57+0,1 * \frac{\mathbf{8 8 2 7 3 6 5 5}}{\mathbf{7 3 4 9 6 5 5 2}}=1,57+0,12=1,69$.

В результате при сравнении нормативного и фактического значений получается: 
$K_{\text {факт }}(1,43)<K_{\text {норматив }}(1,69)-$ риск банкротства по данной методике незначительный.

Далее необходимо рассмотреть модель прогнозирования вероятности банкротства, предложенной Галины Владимировны Савицкой (Белорусский государственный экономический университет). Данная модель построена на 200 производственных предприятиях за период 3 года. Формула расчета интегрального показателя следующая:

$\mathrm{Z}=0,111 * \mathrm{~K}_{1}+13,23 * \mathrm{~K}_{2}+1,67 * \mathrm{~K}_{3}+0,515 * \mathrm{~K}_{4}+3,8 * \mathrm{~K}_{5}$

Коэффициенты рассчитываются по следующим формулам:

$\mathrm{K}_{1}=\frac{\text { Собственный капитал }}{\text { Оборотные активы }}$

$\mathrm{K}_{2}=\frac{\text { Оборотный капитал }}{\text { Собственный капитал }}$

$\mathrm{K}_{3}=\frac{\text { Выручка }}{\text { Среднегодовая величина активов }}$

$\mathrm{K}_{4}=\frac{\text { Чистая прибыль }}{\text { Активы }}$

$\mathrm{K}_{5}=\frac{\text { Собственный капитал }}{\text { Активы }}$

Для $\mathrm{AO}$ «XXX» интегральный показатель в 2016 году имеет следующий вид:

$\mathrm{Z}=0,111 * 1,35+13,23 * 0,74+1,67 * 0,75+0,515 * 0,03+3,8 * 0,37==12,63$

Савицкой:

Оценка предприятия по модели прогнозирования банкротства

Г.В.

$\mathrm{Z}>8$, риск банкротства отсутствует,

$5<Z<8$, риск банкротства небольшой,

$3<\mathrm{Z}<5$, риск банкротства средний,

$1<\mathrm{Z}<3$, риск банкротства большой,

$\mathrm{Z}<1$, риск банкротства предприятия максимальный.

Из этого следует, что риск банкротства АО «ХXX» отсутствует.

Для визуализации составлена сводная таблица 2, в которой отражены все выше представленные методики оценки вероятности банкротства.

Таблица 2

Сводные результаты по методикам банкротства адаптированным к российской экономике на примере $A O$ «XXX»

\begin{tabular}{|c|c|}
\hline $\begin{array}{c}\text { Наименование модели } \\
\text { прогнозирования банкротства }\end{array}$ & Оценка вероятности банкротства \\
\hline $\begin{array}{c}\text { Методика Министерства } \\
\text { финансов }\end{array}$ & $\begin{array}{c}\text { Восстановить платежеспособность за 6 месяцев организации не } \\
\text { удастся, так как коэффициент платежеспособности }=0,96, \text { когда } \\
\text { нормативное значение должно быть больше или ровно 1. }\end{array}$ \\
\hline $\begin{array}{c}\text { Модель Беликова-Давыдовой } \\
\text { Организация по данной методике имеет минимальный риск } \\
\text { банкротства (до 10\%). }\end{array}$ \\
\hline $\begin{array}{c}\text { Модель Зайцевой Ольги } \\
\text { Петровны }\end{array}$ & Риск несостоятельности по данной модели незначительный. \\
\hline $\begin{array}{c}\text { Водель Савицкой Галины } \\
\text { Владимировны }\end{array}$ & Риск банкротства отсутствует. \\
\hline
\end{tabular}

Анализирую данные представленные в таблице можно сделать вывод, что три российские модели из четырех указывают на то, что предприятие $\mathrm{AO}$ «XXX» не имеет риск банкротства или данный риск несостоятельности незначительный.

В результате данного факта возникает противоречие между рассматриваемыми методиками, так как при анализе состава и структуры баланса был выявлен значительный недостаток - заемные средства превышают собственный капитал, вследствие чего нельзя назвать финансовое состояние предприятия $\mathrm{AO}$ «XXX» достаточно устойчивым. Поэтому модель вероятности банкротства Министерства финансов является приемлемой к данной организации. 
Недостатком адаптированных к российской экономике моделей банкротства является дублирование коэффициентов заимствованных из иностранных моделей, что недопустимо значительными особенностями нашей страны.

$$
* * *
$$

1. Российская Федерация. Законы. Федеральный закон от 26.10.2002 г. № 127-Ф3 «О несостоятельности (банкротстве)» [федер. закон: принят Гос. Думой 22 сентября 2002 г (с изм. и доп., вступ. в силу с 01.07.2015)]

2. Дымова И.А, Бровко Т.А. Внутренний контроль и пути его развития / Внедрение результатов инновационных разработок: проблемы и перспективы: сборник статей Международной научнопрактической конференции (8 февраля 2017 г., г. Пермь). В 2 ч. 2. / - Уфа: МЦИИ ОМЕГА САЙНС, 2017. -250 c.

3. Савицкая Г.В. Экономический анализ / Г.В. Савицкая. - М.:ИНФРА-М, 2011.

\section{Гордиенко С.А., Кеслер П.А.}

Изучение инвестиционного проекта по параметрам «Стоимость единицы продукции» и «производительность активов» на оптимизационном программном комплексе

Российский Экономический Университет им. Г.В. Плеханова, Кемеровский институт (филиал) (Россия, Кемерово)

doi:10.18411/spc-8-12-2017-04

idsp: 000001:spc-8-12-2017-04

Тема исследования является актуальной, так как в Российской Федерации открывается множество различных предприятий малого бизнеса, и предпринимателям всегда целесообразно иметь прогноз прибыльности предприятия. Для этого необходимо рассчитывать эффективность инвестиционных и бизнес-проектов в зависимости от различных показателей их внутренней и внешней рыночной среды, в связи с высокими рисками банкротства в нестабильной экономике. Решить задачу выбора эффективной инвестиционной стратегии, без использования методов математического моделирования и автоматизированных программных комплексов финансового анализа, довольно трудно. Используем для этого оптимизационный программный комплекс [1], предназначенный для получения оптимальных объемов инвестиций, производства и финансирования текущей деятельности предприятия на основе концепции [2] и математической модели работы [3]. Проведенные расчеты позволили нам выдвинуть предположение о существенном взаимном влиянии производительности V единицы основных производственных фондов (ОПФ) и рыночной стоимости единицы продукции Ctp на чистую приведенную стоимость (NPV) проекта, имеющего следующие характеристики (см. таблицу 1).

Таблийа 1

Значения параметров проекта

\begin{tabular}{|l|c|c|}
\hline \multicolumn{1}{|c|}{ Наименование параметра проекта } & Эксперимент №1 & Эксперимент №2 \\
\hline Количество видов продукции, шт & 1 & 1 \\
\hline Стоимость единицы ОПФ, д.е. & 80000 & 80000 \\
\hline Стоимость единицы продукции, д.е. & $\mathbf{3 , 5 , 1 0 , 2 0 , 4 0}$ & 28 \\
\hline Срок службы ОПФ, лет & 20 & 20 \\
\hline Производительность ОПФ, ед.пр/едОПФ & 5100 & 5100 \\
\hline Спрос на продукцию, д.е. & 100000 & $\mathbf{2 5 0 0 0 0 , 5 0 0 0 0 0 ,}$ \\
\hline Ставка НДС, доля & 0,18 & 0,18 \\
\hline Ставка НИ, доля & 0,02 & 0,02 \\
\hline Ставка НП, доля & 0,2 & 0,2 \\
\hline
\end{tabular}

